\title{
Insider accounts of dyslexia from research mathematicians
}

\author{
Rachel Lambert ${ }^{1}$ D $\cdot$ Edmund Harriss $^{2}$
}

Accepted: 19 December 2021 / Published online: 7 February 2022

(c) The Author(s) 2022

\begin{abstract}
Within educational research, dyslexia and other disabilities are typically conceptualized as deficits. The theory of neurodiversity encourages researchers to conceptualize cognitive differences as natural forms of human diversity with unique sets of challenges and strengths. Using neurodiversity as our theoretical framework, we analyze the experiences of five research mathematicians with dyslexia as told through personal narratives to find common strengths and challenges for dyslexic thinkers at the highest level of mathematics. We report on 4 themes: (1) highly visual and intuitive ways of mathematical thinking, (2) issues with language and translation between forms, (3) issues with memorization of mathematical facts and procedures, and (4) resilience as a strength of dyslexia that matters in mathematics. We use our participants' insights to explore how neurodiversity, a theory of cognitive disability developed by and for neurodiverse people, could expand opportunities for research. We call for mathematics educators to consider the strengths and challenges of dyslexic learners, as well as valuing expertise from insider perspectives.
\end{abstract}

Keywords Mathematics · Visualization · Neurodiversity $\cdot$ Dyslexia $\cdot$ Language

\section{Introduction}

A critical focus of mathematics reform for the last few decades has been bringing the mathematics taught in K-12 schools closer to mathematicians' actual practice- valuing creativity, visualization, collaboration, and the production of new mathematical knowledge (Hersh, 1999; Lockhart, 2009). This shift is particularly consequential for students with dyslexia or a reading-based learning disability. Dyslexic learners are often challenged by traditional practices of school mathematics, such as rote memorization (de Clercq-Quaegebeur et al., 2018). Yet, there is evidence of cognitive strengths associated with dyslexia that might matter significantly in mathematics, such as three-dimensional spatial thinking (e.g.,

Rachel Lambert

rlambert@ucsb.edu

Edmund Harriss

eharriss@uark.edu

1 Gevirtz Graduate School of Education, University of California Santa Barbara, Santa Barbara,

CA 93106, USA

2 Department of Mathematics, University of Arkansas, Fayetteville, AR 72701, USA 
Attree et al., 2009). However, educational research on dyslexia and mathematics thus far has focused almost exclusively on identifying and remediating deficits of individuals with dyslexia (Lambert \& Tan, 2020). There is a pronounced silence on how strengths might matter for learning mathematics. The neurodiversity movement, developed from the activism of people with autism, dyslexia, and other cognitive differences, ${ }^{1}$ demands that such individuals be understood not as deficient, but as different: part of the natural and beneficial cognitive diversity of society (Walker, 2014).

Learning Disabilities, including dyslexia, are the largest category of disabilities in schools in the USA, representing $37.5 \%$ of students receiving special education services (US Department of Education, 2021). Improving mathematical outcomes is a central goal of mathematics research focused on disability, as students with Learning Disabilities underperform in mathematics (Wei et al., 2013) and are underrepresented in STEM fields (Dunn et al., 2012). Despite the urgency of this problem, educational research cannot hope to understand the relationship between dyslexia and mathematics if research focuses only on cataloguing deficits. By pursuing this asset-based investigation, we hope to find new research directions to better support individuals with dyslexia throughout their mathematical careers. For this reason, we focus on individuals with success in mathematics: research mathematicians. As far as we know, this is the first empirical research project on dyslexic mathematicians.

Using interviews and narrative analysis, this project investigates this issue from the perspective of "neurodiverse insiders" who have experienced learning mathematics with success at the highest levels. Using neurodiversity as our theoretical framework, rather than a deficit or medical model, we analyze the narratives of five dyslexic research mathematicians to find common strengths and challenges. We report on four themes: (1) highly visual and intuitive ways of mathematical thinking, (2) issues with language and "translation" between forms, (3) pronounced issues with memorization of mathematical facts and procedures, and (4) resilience as a strength of dyslexia that matters in mathematics. This study is exploratory in nature, taking a close look at a small set of individuals. As a limited qualitative study, we stress our findings are not generalizable to all dyslexic mathematicians or to all people with dyslexia learning mathematics.

\section{Conceptual framework}

\subsection{Disability studies and neurodiversity}

As researchers and educators, we are committed to recognizing and attending to the humanity of, and individual differences between, disabled people. Drawing from scholarship from Disability Studies (DS) and its sister field in education, Disability Studies in Education (DSE) (Baglieri et al., 2011; Gabel, 2005), we seek to reframe how disability is conceptualized within the mathematics education community. Instead of a medical model (also called a deficit model), we conceptualize disability through a social model; it is the social effects of difference that disable rather than the differences themselves. From the DS and DSE perspective, the medical model depicts disability as deficits located within

\footnotetext{
1 Respectful of differing opinions with the disability community, we use both identity-first language (dyslexic person or dyslexic) and person-first language (a person with dyslexia).
} 
individuals, resulting in identifying, pathologizing, and stigmatizing differences, positioning children with identified disabilities as fundamentally different from "normal" children (Linton, 1998).

To avoid a deficit approach to disability, we rely on neurodiversity as a theory of disability. Developed in the autistic community (Robertson \& Ne'eman, 2008), neurodiversity represents biological fact (the brains of humans are quite different, based on genetic, epigenetic, and environmental development), a separate social movement that advocates for increased access to opportunity for neurodiverse people, and a paradigm shift in how disability is viewed (Walker, 2014). Neurodiversity advocates argue that cognitive differences exist and have both positive and negative implications, depending on the context. The existence of differences does not automatically mean the presence of a deficit. Dyslexia, along with other cognitive differences such as those described as attention-deficit hyperactivity disorder (ADHD) or intellectual disabilities, is increasingly being understood through neurodiversity rather than the medical model of disability (Rappolt-Schlichtmann et al., 2018).

\subsection{Insider perspectives}

Disability Studies and the neurodiversity movement push back against the idea that research can only be done on disabled populations by non-disabled experts. This is embodied by a common rallying cry in both movements, "nothing about us without us" (Charlton, 1998). The theory of action for this cry is to shift expertise to people with disabilities. This study seeks to provide a new lens on the mathematical learning of neurodiverse individuals, grounded in the experiences of those with cognitive differences, rather than the perspectives of researchers who are often neurotypical. Our study is a collaboration between the first author, a neurotypical cis white woman and former classroom mathematics teacher, currently working in mathematics and disability studies at the university level, and the second author, a cis white male research mathematician with dyslexia.

We take a narrative approach to understanding interview data (Chase, 2005; Riessman, 2003, 2007). Narratives are always a reframing of experience, a repositioning of the self among multiple possible selves (Bakhtin, 1981). The structure and content of narratives come from the participants' experiences, but also from how that participant has made sense of their experience over time, as well as the immediate context of the interview (Riessman, 2003). Thus, we do not see narratives of our participants as some kind of final truth about the experience of dyslexia in research mathematics, but as part of the on-going life process of writing and rewriting the self.

\section{Background and context}

\subsection{Dyslexia}

First identified in the 1930s, dyslexia is a hereditary neurobiological disability characterized by difficulties in reading, writing, and spelling, a difficulty that is often unexpected in comparison to other academic skills (Lyon et al., 2003). When "Specific Learning Disability" became a category of special education services under US education policy in the 1960s, these types of differences were reclassified as "Learning Disabilities." Learning Disabilities (LD) has since become a broader category that includes differences in the areas 


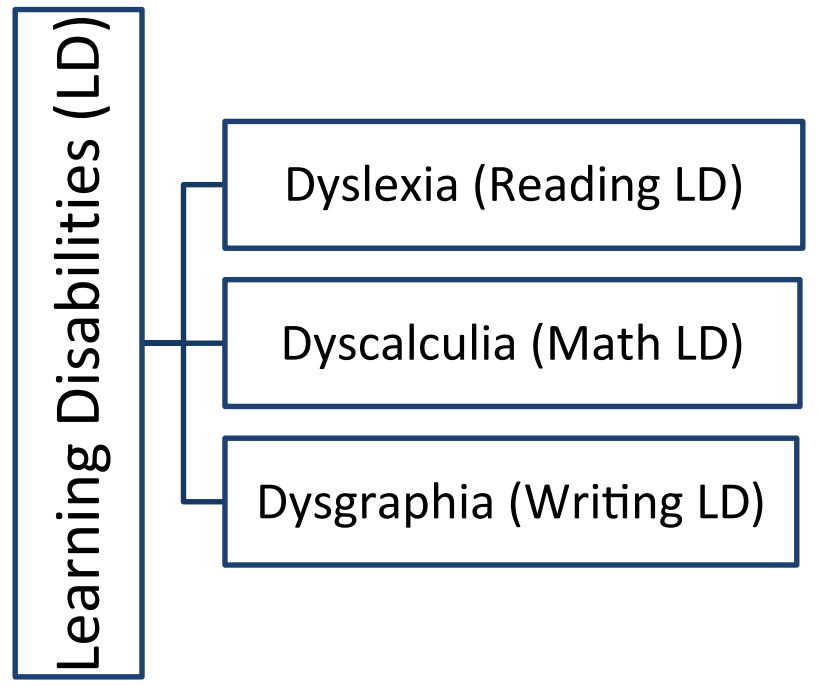

Fig. 1 Learning Disabilities and subcategories

of reading (dyslexia), writing (dysgraphia), and mathematics (dyscalculia) (Fig. 1). Other ways of organizing the subcategories of Learning Disabilities include auditory processing, nonverbal learning disabilities, and/or executive functioning (see Fletcher et al. (2018) for a full review).

The core difficulty in dyslexia is presumed to be difficulties in phonological processing, correlated with difficulties with learning how to read (Lyon et al., 2003; Vellutino et al., 2004). What tends to be consistent across people identified as having LD is some form of processing and/or language difference that significantly affects their performance in school. A significant population of individuals with LD also have diagnoses of ADHD (DuPaul et al., 2013).

Much of the research in LD and mathematics is focused on students with dyscalculia, or significant difficulty learning mathematics (Lambert \& Tan, 2020), a smaller group of students than those with dyslexia. However, students with LD in general, a group comprised of approximately $80 \%$ individuals with dyslexia (Lyon et al., 2003), significantly underperform in mathematics (Wei et al., 2013). The mathematical performance of students with dyslexia or specifically reading LD is understudied, particularly as LD is the largest category of disability served in US Schools (US Department of Education, 2021).

\subsubsection{Strengths in dyslexia}

There has long been speculation about the connection between dyslexia and visual-spatial talents, dating back to Orton in 1925 (Schneps et al., 2007). There is some evidence that people with dyslexia have strengths in visual-spatial thinking, with variations in findings across studies. Some of the differences in findings can be attributed to different ways of defining and assessing visual-spatial thinking (von Károlyi \& Winner, 2004). One strength associated with dyslexia in several research studies is 3-D spatial thinking (von Károlyi \& Winner, 2004), which is connected to strengths in mechanics and complex visualization (Attree et al., 2009). Gilger et al. (2016) disputed these findings, noting that some studies 
on visual spatial skills and dyslexia have found that dyslexic participants' scores are lower on nonverbal spatial abilities when assessed through typical tasks; however, they found evidence that people with dyslexia process spatial information in ways that are different than people without dyslexia (Diehl et al., 2014).

Another strength identified in people with dyslexia is in the category of interconnected reasoning. Everatt et al. (2008) documented that individuals with dyslexia tend to make unique associations between concepts, focused on the big picture. Dyslexic students scored higher than nondyslexics on measures of original thinking (Akhavan Tafti et al., 2009) and on tasks requiring novel and creative solutions (Everatt et al., 1999).

\subsubsection{Mathematics and dyslexia}

In our previous research analyzing the content of special education mathematics research across five years (Lambert \& Tan, 2020), we found that research that includes students with LD (including dyslexia) focuses on (1) identifying cognitive deficits in students and (2) effective interventions for students. This research tends to use a medical model to understand disability. The most common recommended interventions for students with LD are primarily explicit or direct instruction. Compared to research in mathematics education for nondisabled students, there is far less research on students with LD engaged in inquiry mathematics, extended problem solving, or advanced mathematics (see Lambert and Tan (2020) for an extended discussion of this issue and examples of research that does include students with LD in these kinds of mathematics).

Despite dyslexia being a difference in literacy skills, across the population, dyslexic children perform more poorly than non-dyslexic peers on mathematics assessments (Miles et al., 2001). De Clercq-Quaegebeur and colleagues (2018) found that $40 \%$ of dyslexic students had significant issues on more than one mathematical subtest. The majority of dyslexic students (grades 3, 4, and 5) have significant difficulty with digit transcoding (number reading and writing) and mental calculation with pronounced individual differences across dyslexic students (de Clercq-Quaegebeur et al., 2018). Dyslexic children tend to have difficulty recalling arithmetic facts, including multiplication (de Clercq-Quaegebeur et al., 2018; Erenberg, 1995; Miles, 1983; Simmons \& Singleton, 2009). We know of no studies that have investigated dyslexic children's relationship with advanced mathematical topics. Similarly, Lewis and Fisher (2016), analyzing research on dyscalculia, found a dearth of research that investigated mathematical understanding beyond primary school topics.

A small group of studies have investigated questions of basic fact memorization in adults with dyslexia and found evidence that mathematics may be a continued challenge for adults with dyslexia. Three studies on adults with LD found that on a cognitive assessment, the Wechsler Adult Intelligence Scale (WAIS) arithmetic subset was either the lowest or second lowest subtest for dyslexic participants (Blalock, 1987; Cordoni et al., 1981; Vogel \& Walsh, 1987). The only subtest that was lower was the Digit Span subtest, which assesses working memory. Dyslexic adults have documented difficulty in the speed of recall of addition and multiplication facts (Göbel \& Snowling, 2010).

\subsection{Research on the mathematical thinking of mathematicians}

One of the most interesting aspects of our research was to hear mathematicians talk about their approach to mathematics and research. This fits into a tradition going back at least to 1954 with the work of Hadamard on mathematicians' narratives about their work. Other examples 
include the research of Burton $(1999,2004)$ and writings of Gromov (2017). Such studies usually fit within the broader study of mathematical cognition (Danesi, 2019).

One broad theme from this research are conceptualizations of different kinds of mathematical thinking, such as the distinction between visual and analytic thinking, or the distinction between geometric and algebraic thinking (Giaquinto, 2007). These differences can be described as the mathematics of shape and space vs. the mathematics of symbolic manipulation. Drawing from this research, Burton (2004) hypothesized that there were two styles of mathematical thinking: visual and analytic. She also hypothesized that research mathematicians would move between the two styles for different types of problems. In her interviews with 70 research mathematicians, she found instead three styles of mathematical thinking, adding conceptual as multiple participants described this as a qualitatively different thinking style. She also found that only a few of her participants reported moving between all three styles. Some only used one style. In her work (70 total participants), visual styles predominated (45 participants), but she also found participants who used analytic (28 participants) and conceptual styles (33 participants) (participants could use more than one style).

Another topic in this research is mathematical intuition. Working from the same data, Burton (1999) described how the research mathematicians described intuition. While a few rejected the idea of intuition playing a major part in their mathematical thinking, most of the mathematicians described it as being part of their process. Some connected it to visualization, others to the brain making connections across previous knowledge. Some described intuition as a fixed possession, impossible to develop. Burton connected these ideas to epistemological arguments about mathematics as either a fixed body of knowledge or an emergent, creative act. Burton also found that almost all participants reported working collaboratively, a finding which challenges the mythological figure of the mathematician working alone (Burton, 1999).

\subsection{Research questions}

We began this research project wanting to know more about a specific group of dyslexic individuals: research mathematicians. We aligned both our theoretical and methodological decisions with neurodiversity. In terms of methodology, we designed the study to better understand how both strengths and challenges manifest in the mathematical thinking of highly skilled adults with dyslexia, as understanding both strengths and challenges is a key tenet of neurodiversity. We also designed the study to privilege insider perspectives, in this case, research mathematicians with dyslexia, again integrating neurodiversity into our research design. Our research questions are the following:

1. What strengths and challenges do research mathematicians with dyslexia connect to their dyslexia?

2. How do these strengths and challenges relate to mathematics at the highest levels?

\section{Methods}

\subsection{Participants}

Participants were recruited from professional organizations of research mathematicians via emails sent by the second author. A total of five research mathematicians with dyslexia agreed to participate in our study. All were employed at universities in mathematics or 
related STEM departments at the time of our study. Four of them were actively engaged in current mathematical research and one was focused on teaching rather than research.

Three out of the five participants were identified as having dyslexia and/or a reading learning disability during their K-12 schooling. One was given a diagnosis later in life, following the diagnosis of their child. Another participant, who self-identified as dyslexic, had been given a diagnosis of a related disability (ADHD) but identified difficulty reading which significantly affects their daily life. Two of the five participants self-reported a diagnosis of ADHD. One reported significant speech and language delays as a child and another participant self-identified as autistic.

Two out of our five participants identified as cis women, with the other three identifying as cis men. Four out of five participants identified as white. One identified their race as Asian-American. We recognize this lack of racial diversity poses a significant limitation to our work and plan to expand the populations included in future studies. We report data on participants (P1-P5) in the aggregate to avoid identification, as not all participants were comfortable with disclosing their disabilities in their university setting. While we attribute the longer quotes, we purposefully report themes across the interviewees, rather than describing each individual as a case study. We also use the pronoun "they" to avoid identification of participants by gender.

\subsection{Data collection}

The first and second author together interviewed each participant for between 60 and 90 minutes. The first author is an experienced qualitative interviewer. The second author, as an expert in mathematics, provided follow-up questions on mathematical content. The interview was semi-structured with questions in the following categories: (1) description of current mathematical work, (2) school experiences in mathematics, (3) school experiences and diagnosis of dyslexia, and (4) connections between dyslexia and mathematics. See Appendix 1 for questions. We designed the interview to elicit narratives using an interactional style of interviewing (Chase, 2005). The second author, also a dyslexic mathematician, engaged in discussion as well as listening, drawing out participants to speak more about their thought processes. Interviews were video-recorded and then transcribed.

\subsection{Data analysis}

Our unit of analysis was narratives within the interview transcripts. Narratives in interviews tend to fall into particular genres (Riessman, 2003, 2007), with different kinds of narratives demonstrating different structures and necessitating different analysis processes. Based on our experience with previous interviews about mathematics history, we initially looked for two genres of narratives within the interview data. The first we identified as Life History Narratives, typical retrospective narratives retelling a life event. These typically followed a narrative structure, with a beginning, middle, and conclusion (Labov \& Waletzky, 1997). We also identified a kind of narrative we called Narratives of Thinking, which we defined as nontraditional narratives without a set sequence of events but with an experiential description of how it feels to think in a certain way, here related to mathematical thinking and problem solving. The first author used a similar definition of narratives in a previous study (Lambert, 2019). All narratives were coded by the first author for the 
initial round in the data analysis program, Dedoose. Narratives were extracted from transcripts and coded as either Life History Narratives or Narratives of Thinking.

\subsubsection{Coding for life history narratives}

These narratives were coded thematically (Riessman, 2007) with both a priori and emergent coding. A priori categories and codes for this phase were: Life Phase of Narrative (ex. childhood/elementary school or graduate school); Subject in School (ex. writing or math); Mathematical Topics (ex. topology); Mathematical Strengths; Mathematical Challenges. Codes comparing strengths and challenges were determined a priori from the theory of neurodiversity, which stresses the importance of both strengths and challenges. Emergent codes included collaboration, resilience, and difficulties with memorization, both discussed by multiple insiders. The first author reorganized codes, recoded all narratives, and then prepared a set of memos on each topic for collaborative discussion with both authors.

\subsubsection{Coding for narratives of thinking}

Analysis of these narratives followed a different process, as we were not initially classifying these narratives into previously determined categories, such as Life Phase of Narrative. Instead, we sought to understand how these participants understood their own cognitive processes. Analysis was done through open and in vivo coding, with codes emerging from the descriptions of the participants such as "visualization" and "linear thinking," terms used by participants. Because of the emergent nature of this analysis, and because there were fewer of these narratives, all of these narratives were combined in a single memo on Narratives of Thinking. Analysis across these narratives was done collectively in multiple meetings by both researchers.

Our next set of meetings integrated the analysis of the two kinds of narratives, with the four themes in this paper emerging from this analysis. Themes 1 and 2 were particularly derived from analysis of Narratives of Thinking, while Themes 3 and 4 included both kinds of narratives, but more influenced by Life History Narratives. All issues around coding and analysis were resolved during these collaborative sessions. A third round of analytic memos was created to document the evidence for the 4 themes identified in this paper, as well as a memo on life history and the mathematical areas of the participants. A draft of the final paper was sent to participants for a member check, who endorsed the themes that we presented.

\section{Findings}

We begin by describing the mathematical areas of participants. We briefly explore the paths participants took to a career in mathematics, including experiences learning mathematics in K-12 schools. We then explore four larger themes found in our interviews: (1) highly visual and intuitive ways of mathematical thinking, (2) issues with language and "translation" between forms, (3) pronounced issues with memorization of mathematical facts and procedures, and (4) resilience as a strength of dyslexia that matters in mathematics. 


\subsection{Mathematical focus of participants}

Participants had a wide range of mathematical interests, from mathematical visualization through algebraic topology, functional analysis, and mathematical physics. All participants worked in a broad sense on spatial questions, with two participants working on the geometry of three dimensions. The other three participants worked on spatial structures, with one accessed by a more algebraic approach.

The most notable commonality across participants was the level of diversity in the mathematics each individual's work required. All participants seemed to work broadly and make connections between mathematics and other areas. As one participant noted, "I really like being involved in more than one thing, and I get kind of bored if I stay in one area for a really long time, then I start looking around for something else that might interest me" (P5). Another offered, "As you can see, I'm also somebody who likes to take weird side paths" (P3). There seemed to be a commonality in a desire to find ways to connect mathematical topics and mathematics to outside topics including art, education, and science.

\subsection{Pathway to mathematics as a career}

All participants identified reading and writing as a significant concern in their early schooling. Two participants reported learning to read in 6th and 7th grade, much later than their peers. Others recalled being able to decode text but had significant challenges with spelling and writing that persisted into adulthood. Four members of the group identified mathematics as an early strength, especially when compared to subjects that were reading intensive: "Mathematics was something I could do where reading and writing weren't as strong a factor, and the logic of how to figure things out was. And I loved proving things. I loved figuring things out" (P2). Other identified strengths included science and art. One participant shared they had been identified as gifted in mathematics and were moved to a more challenging class, but then moved back following inconsistent performance in the higher mathematics class. It was the participant's sense that the school did not understand where they fit as a student; they had a natural affinity for mathematics but did the mathematics in unusual ways.

Several participants noted barriers that either slowed or could have completely stopped their progress in mathematics. For one it was calculus, another organic chemistry. Both of these classes required large amounts of memorization to be successful. One participant identified mathematics as a significant struggle until high school geometry, "I struggled quite a bit, and I didn't like math until we got to geometry" (P3). All participants noted that they moved forward in mathematics once they reached a place in which they were fascinated by the problems, most often, a visual-spatial set of problems.

The second factor that moved participants to mathematics was relationships and collaboration. For one participant, graduate school in mathematics was initially seen as a stopgap on their way to other career plans. But once they entered, they found a place in which there was community and collaboration, "I felt comfortable there" (P2). Two participants mentioned the important role of small study groups which allowed for extended discussion of mathematical ideas. Three participants noted that relationships with mentors cemented their careers as mathematicians. All participants mentioned collaboration as critical to their current work, as necessary for them to develop new mathematical knowledge. 
We noticed that all of the participants saw their dyslexia as simply a part of who they were as a person and a mathematician. All participants described dyslexia as a set of strengths and challenges, although the specifics varied between participants. P4 noted, "the dyslexia... I explain to people, it's sort of like you're strong in one thing, but it makes you weak in others."

\subsection{Theme \#1: highly visual and intuitive ways of mathematical thinking}

All participants described a history of unusual ways of solving mathematical problems. Two interrelated subthemes emerged in this theme: visualization and intuition.

\subsubsection{Visualization}

Four out of five participants repeatedly brought up visualization as a personal strength in their own mathematical thinking. In multiple interviews, participants proposed a cognitive duality echoed in the literature (e.g., Burton, 2004; Hadamard, 1954): "verbal" vs. "visual" or "algebraic" vs. "geometric." Four out of five participants identified as visual and/ or geometric mathematical thinkers, with P1 noting that they learn through "geometry first, thinking through space" and "I can do immensely technical work in images that others can do in language." Another participant indicated they chose their mathematical topic based on their preference for visual thinking, specifically "picture drawing and the topology of it" (P2).

P4 described a strong predilection for thinking visually, not just in mathematics but across topics: "Well my entire memory is sort of visual, it's like playing back little snippets of film." They became interested in "three-dimensional geometry and topology. Anything that I can draw or sculpt or anything that's like three dimensional and sort of visual-based." Once when struggling in a physics class in their graduate work, they saw a particular image in the text (vector fields on a surface) and suddenly, the "pictures made it make sense." P4 prefers to not only think with visuals, but to write with them as well, noting a strong preference for storyboarding mathematical papers using a series of images.

Another participant identified as both:

A details kind of thinker and like a visual thinker. I can't get interested in the details unless I have the picture that I think I'm working out the details for. But, once I have a picture of what I think should be going on, then the details become interesting . . . It's not the other way around. (P5)

One participant noted the importance of visuals when discussing complex mathematical ideas, telling a story about being at a mathematics conference and having difficulty engaging with a verbal discussion of a new mathematical idea, and then returning to their hotel room and drawing out the idea with visuals. According to this participant, their engagement with this mathematical discussion would have been completely different if there had been a whiteboard.

Three out of five participants at some point in their interviews suggested their dyslexia may have been connected to a way of seeing mirror images and/or symmetries in geometric shapes and algebraic equations. "Well," said P2, "I think I saw symmetries, I saw equations easily because of it. Because my brain would flip things around very easily. I understood equations quickly and easily because of my dyslexia." One participant wondered aloud if, "Somehow dyslexic thinking is naturally commutative?" (P1). This may relate to 
the experience of some dyslexics of "flipping letters" as they read (Lambert et al. 2019) . Two participants noted that they still commonly transposed digits as adults, something that proved challenging when writing on the board during teaching. They attributed this to their dyslexia.

\subsubsection{Intuition}

Four out of five participants specifically described visual thinking and used the phrases "flexible," "creative," or "out of the box" when talking about their solutions to complex problems. P3 shared,

I talk in ghosts and mists. My brain seems to be really, really comfortable with just throwing out ideas. It just really is very flexible. It doesn't like boxes. It's just very, very flexible. And so, I get a sense that something is true, or something that I want, I need, is there. And then my brain really doesn't get bothered by the fact that some ideas don't work, it just will throw out lots and lots of ideas and sort of wander. And that drives co-authors nuts, because they'll say, 'Oh, I see? That idea doesn't work.' And it doesn't slow me down one bit. My brain just has like five other weird ideas, two of which you can throw out immediately, and the three others you have to spend time on. And it just sort of keeps working that way.

P1 noted their personal strengths in mathematics as:

Coming out with the idea that pushes you beyond the routine. So thinking about things, especially a visual or spatial ideas ... So sort of coming up with ideas that are not in the routine, especially things that are related to images.

\subsection{Theme \#2: issues with language and "translation" between forms}

All participants noted difficulties with language in relationship to mathematics. This included translating mathematical thinking into text, as well as understanding mathematical talk without the support of images. Another issue was communicating mathematical thinking through talk. These difficulties with language included struggles with writing. Most of them mentioned spelling difficulties in childhood and adulthood, as well as general difficulties with writing that had not gone away.

The most significant concern mentioned in the interviews for these research mathematicians was academic mathematical writing. Two participants noted difficulties with writing because it was so linear, which felt different to how they understood the mathematics. P1 noted, "the fact that writing is ... there's one order to it. My ideas in my head are rarely linear. There's one thing and that connects to three things." P4 also mentioned the linear nature of text as a problem: "I find also when I write... that I don't write linearly."

Three participants discussed how it was a struggle to write up mathematical findings even after the mathematics itself was understood. This was especially a problem for one pre-tenure participant. They shared they had significantly fewer publications because of their difficulty translating their understanding of the mathematics into academic writing. This challenge was echoed by two of the mathematicians, both senior members of their faculty. P5 noted that they enjoyed the challenge of writing up mathematical findings, but 
it took a significant amount of time. P3 described a complete lack of interest in the work needed to write up mathematical findings:

And the worst part is, once I solve them, I have no interest in writing them down. I find writing very difficult, so...All that work to try to explain to you why this was really true, and why you should think about it this way...

\subsection{Theme \#3: issues with memorization of mathematical facts and procedures}

The one consistent difficulty in elementary school mathematics mentioned by all participants was difficulty with the times tables and/or memorizing mathematical procedures. Some brought this up spontaneously, but others clearly did not connect memorization of facts to mathematics. In this exchange with P2, the first author is asking whether or not they had any difficulties with mathematics in K-12.

Dr. Lambert: Was there any part of math, like in elementary school, middle school, or high school that was challenging for you?

P2: No.

Dr. Lambert: So, memorization of facts was not challenging for you?

P2: Oh, I never could memorize anything. I had to derive everything . . . Yeah, I've never been good at memorizing things, just like I couldn't memorize how to spell words, I couldn't memorize facts in math. So I paid attention in class, and I had good enough teachers that they derived everything. And I figured out how to derive everything I needed to know, and I just derived everything I needed to know. You take a trig class, for instance, okay ... I know the trig identity for sin of alpha plus beta. From that trig identity, I can derive all the other ones. And then if I needed any of them, I would just do that. But I never actually like memorized them. I still don't memorize them.

P2 also noted that they attended a particularly progressive elementary school with no tests or quizzes in mathematics. P1 noted that their mother taught the multiplication tables through a smaller set of memorized facts, specifically the squares, and then encouraged P1 to build equations through the distributive property from known facts.

In addition to the multiplication tables, participants noted the difficulty of any kind of memorization "without structure." P1 notes,

That is one of the reasons I'm slower. I have really good memory for connected facts. I can't remember phone numbers at all. Learning foreign languages was the one bit of school that I hated because you have this long list of words that had no connection to anything. So memorization without structure. So I memorized the structure.

Another participant shared their history of understanding "concepts" in mathematics but struggling with "the details." When we asked what they meant by details, they told a story about being negatively judged for their lack of memorization of the multiplication tables in elementary school:

I could've explained to you with a picture why nine times five was 45 , and my friends could tell you that it was 45 but they couldn't tell you why. And it struck me as really upsetting that someone that, just memorizing that number, was valued more than me 
understanding why that was the right answer. And it's always been a problem. But it just seems to me that why something is true is much more important than knowing that it is true. (P3)

Several participants noted that their difficulties with memorization were connected to the expectation of speed connected to memorization. Not only was memorization without structure very challenging, but participants were also asked to do this task under time pressure.

\subsection{Theme \#4: developing strengths through struggle}

Four out of five participants identified resilience as a strength of dyslexia. More specifically, participants noted that working through challenges made them more resilient and able to persevere, which became a considerable strength for them in higher mathematics. When asked what a strength of dyslexia is, P2 said, "Resiliency, I guess. Just being able to kind of overcome things that are not necessarily the easiest for you." P5 described their "coping mechanisms" as:

Basically being comfortable with the fact that I'm not going to be fast at a lot of things. And, being okay with not being fast . . . The fluency tests really make you think that speed is the whole deal. And, it was really important for me to sort of realize that no, that's not what matters.

Success in mathematics, participants noted, comes with hard work. Because mathematics is hard for almost everyone, understanding what to do when the mathematics is hard is a gift for a mathematician. As P1 notes,

Sort of actually everyone is facing struggles. Calculus is hard for most people. And so what we can understand about how people get through it when they have greater struggles is really useful for the people who are having smaller versions of those same struggles.

Several participants noted that their challenges made them better teachers of mathematics.

\section{Discussion}

In this article, we sought to develop new understandings about the relationship between dyslexia and mathematics through the insider perspectives of highly skilled dyslexic adults. Our research challenges the deficit-based approach typically used in educational research with students with dyslexia, thus potentially opening new avenues of educational research that move beyond the medical model of disability. Specifically, we understand dyslexia through neurodiversity, which allows us to analyze both challenges and strengths. While the medical model allows only analysis of deficits, neurodiversity repositions disability as a contextual set of strengths and challenges. This mirrors how our participants understood dyslexia after a lifetime of experiencing it: as strengths and challenges. In addition, neurodiversity led us to value insider experience, which can contribute unique and particularly valuable insights about a phenomenon. 
The first strength discussed by participants was visual spatial reasoning, supported by some studies on visual spatial reasoning strengths for individuals with dyslexia (e.g., Attree et al., 2009). Visuals were not ancillary to the mathematical process for our participantsthey seemed to think with and through these representations. These ways of thinking visually were well suited to their mathematical fields of study. All of the mathematicians interviewed here fitted more into the visual or geometric style, rather than the algebraic (Giaquinto, 2007).

A second strength, reported by all participants without prompting, was an unusual way of approaching mathematical problem solving. Their way of solving problems was seen by others as "out of the box," "very, very flexible," and "pushing beyond the routine." We see connections between this finding and research on dyslexic strengths in interconnected reasoning, including unique connections between concepts (Everatt et al., 2008), original thinking (Akhavan Tafti et al., 2009), and creativity for tasks requiring novelty (Everatt et al., 1999).

A final strength mentioned by four out of five participants was resilience. These participants particularly noted that some aspects of mathematics took them more time: "I'm not going to be fast at a lot of things" (P5). Speed did not matter as much to them as the quality of their mathematical thinking. The issue of fast versus slow in mathematics goes well beyond dyslexic individuals. Many mathematics teachers use descriptors like "slow" and "fast" to categorize students (Horn, 2007). In previous studies, we found middle school students with LD who felt pigeon-holed as "slow" by others but had begun to redefine what that meant (Lambert, 2017, 2019). Just like these adult research mathematicians, these young people redefined "slow" to include success in mathematics. Perhaps these narratives of being "slow" from dyslexic research mathematicians could assist more young people with dyslexia/LD to question this assumption that fast is preferable in mathematics.

Participants also identified challenges such as memorization. Memorization of facts and procedures has been well documented as a significant and persistent difficulty for individuals with dyslexia (de Clercq-Quaegebeur et al., 2018), including in adulthood (Göbel \& Snowling, 2010). For these mathematicians, a lack of automaticity of multiplication facts did not seem to negatively affect their work. Participants reported deriving facts or using the kind of reconstructive strategies used by successful dyslexic students (Erenberg, 1995). This issue with memorization only became a problem for participants in early school mathematics, when a particular teacher was rigidly focused on memorization. Participants noted that these teachers and classes almost caused them to turn away from mathematics and STEM in general.

A second challenge found across participants was a persistent difficulty communicating mathematical ideas. This included difficulties writing up mathematical findings, talking about mathematics in prescribed ways, and listening to mathematical discussions without visual support. At the same time, participants noted how critical mathematical talk was for developing their thinking, particularly in collaborative groups. These mathematicians reported enjoying engaging in less formal and rigid kinds of discussions and collaborations. Participants discussed how writing in a linear way was particularly hard when mathematical ideas felt like a "interconnected web of ideas" (P1). For multiple participants, writing up research findings was a barrier.

It is worth noting that in general the stories told here fit comfortably into a tradition of previous research on mathematicians describing their own thinking, research that does not specifically mention neurodiversity. Our participants also valued collaboration, just as those in Burton's study (2004) did. While all our participants described solving problems visually, so did the majority of participants in Burton's study of 70 mathematicians (1999, 
2004). Most of our participants also discussed the importance of intuition, which was also a theme in Burton's interviews (1999).

However, some of the challenges we identified in our interviews for dyslexic mathematicians do not appear in the previous research literature on mathematicians' thinking. While in Burton's study (2004), mathematicians described a primary mathematics focused on facts and memorization as being unfulfilling, memorization is not described as a barrier. We also do not see studies that document a similar sense of how challenging mathematical writing was for our participants. These may be interesting areas to explore to increase accessibility to STEM for all learners.

Finally, we note that while our analysis was focused on themes across participants, there was diversity within and across our set of participants. While we emphasize commonalities for the purposes of this paper, experiences of our participants were quite different. For example, two out of five of our participants noted significant challenges transcribing numerals, while others did not experience that difficulty. Yet there is a common conception that dyslexia is "flipping letters," something that some individuals with dyslexia report and others do not (Lambert et al., 2019). We stress that the individual differences across neurodiverse learners are critical and should not be overlooked.

\section{Limitations}

We caution readers that when we report that four out of five interviewees noted their own strengths in visual thinking, we are not suggesting that $80 \%$ of people with dyslexia are visual thinkers or that $80 \%$ of dyslexic mathematicians share this tendency. Our small set of studies is an opportunity to identify some common themes within a small, specific subgroup of the dyslexic population. We would need significantly different research to answer questions about how these preferences apply across people with dyslexia more broadly. We recognize the limited demographics of our sample as a limitation. We also recognize our study attracted individuals who were interested in and comfortable with talking about their dyslexia, which possibly created a group that was more positive about dyslexia than a random group.

\section{Implications}

Our intention with this research is to begin a research program about the under-studied population of dyslexic mathematicians, with the understanding that such research can inform K-12 mathematics education. In future studies, we hope to learn more about dyslexia and mathematics at the university level. This includes what supports dyslexic students to persist in STEM careers and what pedagogical innovations support mathematics learning for these students. A more diverse participant set in terms of race and gender would be important to better understand how multiple positionings and intersectionality matter in terms of mathematical career pathways (Leyva, 2016). We wonder what institutional barriers might exist at the intersections of race, gender, and disability. In addition, we hope to see additional research on multiple disability categories, exploring the experiences and insights of blind, deaf, and autistic mathematicians for example. Such research could help us expand STEM accessibility for neurodiverse and disabled students at all levels of schooling. 
We see the need for neurodiversity as a theoretical framework to be incorporated in more research on dyslexia and mathematics at all academic levels. Currently, research on dyslexic strengths and deficits are treated as separate areas of study, with research on deficits far outnumbering research on strengths. As research begins to explore possible subgroups of mathematical learners within dyslexia, we insist that a consideration of strengths be included. For research to truly capture the complexity of dyslexia in terms of mathematics, strengths must be better understood, as well as challenges.

\section{Appendix}

\section{Interview Questions}

1. What do you do now? How did you get into that field? (Prompt for any particular barriers to entering that field or particular strengths related to the area, for narratives about becoming a mathematician)

2. Tell us about an important moment in your mathematical career. What happened, and what was your process? Any mathematical ideas that did not work? (Prompt for discovery narratives, prompt for thinking about collaboration, what you do with negative feedback)

3. What kinds of mathematical work do you enjoy? What kind of thinking suits you? Why? (Prompt for thinking narratives)

4. Tell us about your history with mathematics in school, out of school. (Prompt for K-12 experiences if not yet covered)

5. What were your experiences like with dyslexia? In school? What about as an adult?

6. What connections do you see, if any, between mathematics and dyslexia?

7. Do you have any questions about the study?

Availability of data and material Not applicable

Code availability Not applicable.

\section{Declarations}

Ethics approval This study was approved by the Human Research Board at University of California Santa Barbara.

Consent to participate Participants gave consent to participate through signed consent documents.

Consent for publication I have permission from my coauthor to submit this paper.

Conflict of interest The authors declare no competing interests.

Open Access This article is licensed under a Creative Commons Attribution 4.0 International License, which permits use, sharing, adaptation, distribution and reproduction in any medium or format, as long as you give appropriate credit to the original author(s) and the source, provide a link to the Creative Commons licence, and indicate if changes were made. The images or other third party material in this article are included in the article's Creative Commons licence, unless indicated otherwise in a credit line to the 
material. If material is not included in the article's Creative Commons licence and your intended use is not permitted by statutory regulation or exceeds the permitted use, you will need to obtain permission directly from the copyright holder. To view a copy of this licence, visit http://creativecommons.org/licenses/by/4.0/.

\section{References}

Akhavan Tafti, M., Hameedy, M. A., \& MohammadiBaghal, N. (2009). Dyslexia, a deficit or a difference: Comparing the creativity and memory skills of dyslexic and nondyslexic students in Iran. Social Behavior and Personality, 37(8), 1009-1016. https://doi.org/10.2224/sbp.2009.37.8.1009

Attree, E. A., Turner, M. J., \& Cowell, N. (2009). A virtual reality test identifies the visuospatial strengths of adolescents with dyslexia. CyberPsychology \& Behavior, 12(2), 163-168. https://doi.org/10.1089/ cpb.2008.0204

Baglieri, S., Valle, J. W., Connor, D. J., \& Gallagher, D. J. (2011). Disability studies in education: The need for a plurality of perspectives on disability. Remedial and Special Education, 32(4), 267-278. https:// doi.org/10.1177/0741932510362200

Bakhtin, M. M. (1981). The dialogic imagination. University of Texas Press.

Blalock, J. (1987). Intellectual levels and patterns. In D. Johnson \& J. Blalock (Eds.), Young adults with learning disabilities: Clinical studies. Grune and Stratton.

Burton, L. (1999). Why is intuition so important to mathematicians but missing from mathematics education? For the Learning of Mathematics, 19(3), 27-32.

Burton, L. L. (2004). Mathematicians as enquirers: Learning about learning mathematics. Springer.

Charlton, J. I. (1998). Nothing about us without us: Disability oppression and empowerment. University of California Press.

Chase, S. E. (2005). Narrative inquiry: Multiple lenses, approaches, voices. In W. Luttrell (Ed.), Qualitative educational research: Readings in reflexive methodology and transformative practice (pp. 651-680). Routledge.

Cordoni, B., O’Donnell, J., Ramaniah, N., Kurtz, J., \& Rosenshein, K. (1981). Wechsler adult intelligence score patterns for learning disabled young adults. Journal of Learning Disabilities, 14, 404-407.

Danesi, M. (Ed.) (2019) Interdisciplinary perspectives on math cognition. Springer International Publishing.

De Clercq-Quaegebeur, M., Casalis, S., Vilette, B., Lemaitre, M.-P., \& Vallée, L. (2018). Arithmetic abilities in children with developmental dyslexia: Performance on French ZAREKI-R Test. Journal of Learning Disabilities, 51(3), 236-249. https://doi.org/10.1177/0022219417690355

Diehl, J. J., Frost, S. J., Sherman, G., Mencl, W. E., Kurian, A., Molfese, P., Landi, N., Preston, J., Soldan, A., Fulbright, R. K., Rueckl, J. G., Seidenberg, M. S., Hoeft, F., \& Pugh, K. R. (2014). Neural correlates of language and non-language visuospatial processing in adolescents with reading disability. NeuroImage, 101, 653-666. https://doi.org/10.1016/j.neuroimage.2014.07.029

Dunn, C., Rabren, K. S., Taylor, S. L., \& Dotson, C. K. (2012). Assisting students with high-incidence disabilities to pursue careers in science, technology, engineering, and mathematics. Intervention in School and Clinic, 48(1), 47-54. https://doi.org/10.1177/1053451212443151

DuPaul, G. J., Gormley, M. J., \& Laracy, S. D. (2013). Comorbidity of LD and ADHD: Implications of DSM-5 for assessment and treatment. Journal of Learning Disabilities, 46(1), 43-51. https://doi.org/ $10.1177 / 0022219412464351$

Erenberg, S. R. (1995). An investigation of heuristic strategies used by students with and without learning disabilities. Learning Disabilities: A Multi-Disciplinary Journal, 6(1), 9-12.

Everatt, J., Steffert, B., \& Smythe, I. (1999). An eye for the unusual: Creative thinking in dyslexics. Dyslexia, 5(1), 28-46. https://doi.org/10.1002/(SICI)1099-0909(199903)5:1\%3c28::AID-DYS126\%3e3.0. $\mathrm{CO} ; 2-\mathrm{K}$

Everatt, J., Weeks, S., \& Brooks, P. (2008). Profiles of strengths and weaknesses in dyslexia and other learning difficulties. Dyslexia, 14(1), 16-41. https://doi.org/10.1002/dys.342

Fletcher, J. M., Lyon, G. R., Fuchs, L. S., \& Barnes, M. A. (2018). Learning disabilities (2nd ed.). Guilford Publications.

Gabel, S. L. (Ed.) (2005). Disability studies in education: Readings in theory and method (Vol. 3). Peter Lang.

Giaquinto, M. (2007). Visual thinking in mathematics: An epistemological study. Clarendon Press.

Gilger, J. W., Allen, K., \& Castillo, A. (2016). Reading disability and enhanced dynamic spatial reasoning: A review of the literature. Brain and Cognition, 105, 55-65. https://doi.org/10.1016/j.bandc.2016.03. 005 
Göbel, S. M., \& Snowling, M. J. (2010). Number-processing skills in adults with dyslexia. Quarterly Journal of Experimental Psychology, 63(7), 1361-1373. https://doi.org/10.1080/17470210903359206

Gromov, M. (2017) Math currents in the brain. In R. Kossak \& P. Ording (Eds.), Simplicity: Ideals of practice in mathematics and the arts. Springer.

Hadamard, J. (1954). The mathematician's mind: The psychology of invention in the mathematical field. Princeton University Press.

Hersh, R. (1999). What is mathematics, really? Oxford University Press.

Horn, I. S. (2007). Fast kids, slow kids, lazy kids: Framing the mismatch problem in mathematics teachers' conversations. Journal of the Learning Sciences, 16(1), 37-79. https://doi.org/10.1080/1050840070 9336942

Labov, W., \& Waletzky, J. (1997). Narrative analysis: Oral versions of personal experience. Journal of Narrative and Life History, 7, 3-38.

Lambert, R. (2017). 'When I am being rushed it slows down my brain': Constructing self-understandings as a mathematics learner. International Journal of Inclusive Education, 21(5), 521-531. https://doi.org/ 10.1080/13603116.2016.1251978

Lambert, R. (2019). Political, relational, and complexly embodied; experiencing disability in the mathematics classroom. ZDM-Mathematics Education, 51(2), 279-289. https://doi.org/10.1007/ s11858-019-01031-1

Lambert, R., Chun, M., Davis, J., Ceja, K. L., Aguilar, K., Moran, P., \& Manset, L. (2019). "My dyslexia is like a bubble": How insiders with learning disabilities describe their differences, strengths, and challenges. Learning Disabilities: A Multidisciplinary Journal, 24(1), 1-18. https://doi.org/10.18666/ LDMJ-2019-V24-I2-8765

Lambert, R., \& Tan, P. (2020). Does disability matter in mathematics educational research? A critical comparison of research on students with and without disabilities. Mathematics Education Research Journal, 35, 5-35. https://doi.org/10.1007/s13394-019-00299-6

Lewis, K. E. \& Fisher, M. B. (2016). Taking stock of 40 years of research on mathematical learning disability: Methodological issues and future directions. Journal for Research in Mathematics Education, 47(4), 338-371. https://doi.org/10.5951/jresematheduc.47.4.0338.

Leyva, L. A. (2016). An intersectional analysis of Latin@ college women's counter-stories in mathematics. Journal of Urban Mathematics Education, 9(2). http://ed-osprey.gsu.edu/ojs/index.php/JUME/article/ view/295

Linton, S. (1998). Claiming disability: Knowledge and identity. NYU Press.

Lockhart, P. (2009). A mathematician's lament: How school cheats us out of our most fascinating and imaginative art form. Bellevue Literary Press.

Lyon, G. R., Shaywitz, S. E., \& Shaywitz, B. A. (2003). A definition of dyslexia. Annals of Dyslexia, 53(1), 1-14. https://doi.org/10.1007/s11881-003-0001-9

Miles, T. R. (1983). Dyslexia: The pattern of difficulties. Whurr.

Miles, T. R., Haslum, M. N., \& Wheeler, T. J. (2001). The mathematical abilities of dyslexic 10-year-olds. Annals of Dyslexia, 51(1), 299-321. https://doi.org/10.1007/s11881-001-0015-0

Rappolt-Schlichtmann, G., Boucher, A. R., \& Evans, M. (2018). From deficit remediation to capacity building: Learning to enable rather than disable students with dyslexia. Language, Speech \& Hearing Services in Schools, 49(4), 864-874. https://doi.org/10.1044/2018_LSHSS-DYSLC-18-0031

Riessman, C. K. (2003). Performing identities in illness narrative: Masculinity and multiple sclerosis. Qualitative Research, 5-33 vol. 3. https://doi.org/10.1177/146879410300300101

Riessman, C. (2007). Narrative methods for the human sciences. Sage Publications, Inc.

Robertson, S. M., \& Ne'eman, A. D. (2008). Autistic acceptance, the college campus, and technology: Growth of neurodiversity in society and academia. Disability Studies Quarterly, 28(4). http://dsq-sds. org/article/view/146/146

Schneps, M. H., Rose, L. T., \& Fischer, K. W. (2007). Visual learning and the brain: Implications for dyslexia. Mind, Brain, and Education, 1(3), 128-139. https://doi.org/10.1111/j.1751-228X.2007.00013.x

Simmons, F. R., \& Singleton, C. (2009). The mathematical strengths and weaknesses of children with dyslexia. Journal of Research in Special Educational Needs, 9(3), 154-163.

US Department of Education. (2021). 42th annual report to congress on the implementation of the Individuals with Disabilities Education Act. http://www.ed.gov/about/reports/annual/osep.

Vellutino, F. R., Fletcher, J. M., Snowling, M. J., \& Scanlon, D. M. (2004). Specific reading disability (Dyslexia): What have we learned in the past four decades? Journal of Child Psychology \& Psychiatry, 45(1), 2-40. https://doi.org/10.1046/j.0021-9630.2003.00305.x

Vogel, S. A., \& Walsh, P. C. (1987). Gender differences in cognitive abilities of learning- disabled females and males. Annals of Dyslexia, 37, 142-165. 
von Károlyi, C., \& Winner, E. (2004). Dyslexia and visual spatial talents: Are they connected? In T. M. Newman \& R. J. Sternberg (Eds.), Students with both gifts and learning disabilities: Identification, assessment, and outcomes (pp. 95-117). Springer US. https://doi.org/10.1007/978-1-4419-9116-4_6

Walker, N. (2014), Neurodiversity: Some basic terms and definitions, Neurocosmopolitanism. https://neuro cosmopolitanism.com/neurodiversity-some-basic-terms-definitions/. Retrieved June 17, 2016.

Wei, X., Lenz, K. B., \& Blackorby, J. (2013). Math growth trajectories of students with disabilities: Disability category, gender, racial, and socioeconomic status differences from ages 7 to 17 . Remedial and Special Education, 34(3), 154-165. https://doi.org/10.1177/0741932512448253

Publisher's note Springer Nature remains neutral with regard to jurisdictional claims in published maps and institutional affiliations. 